\title{
IDOLATRIA, ORDEM E BELEZA: O CAMINHO DE RETORNO AO Absoluto segundo o De Vera Religione de Santo Agostinho
}

\author{
Joel Gracioso ${ }^{1}$
}

Resumo: Este artigo pretende expor a relação entre idolatria, ordem, beleza e interioridade na perspectiva agostiniana, a partir de sua obra De vera religione.

Palavras-Chave: Idolatria. Ordem. Beleza. Interioridade.

Agostinho, no De vera religione, após abordar a especificidade do cristianismo e da Igreja contrapondo a doutrina cristá ao pensamento maniqueísta, analisa justamente a problemática do mal mostrando, a partir de uma metafísica otimista, que o mal não possui positividade ontológica. Ademais, explicita em que medida a salvação do humano vem pela fé e pela razão. Todavia, mesmo abordando tais questôes, permanece uma dúvida que sempre o inquietou: qual a origem do mal?

No entendimento do doutor de Hipona, analisar tal questão implica investigar a origem do pecado, da impiedade.

Do capítulo 36 até o capítulo 40, Santo Agostinho trata justamente destas questóes, analisando primeiramente a origem da impiedade e da necessidade de se retornar à primeira beleza. Num segundo momento explicita a importância da interioridade.

\footnotetext{
${ }_{1}^{1}$ Professor na Faculdade São Bento de São Paulo, São Paulo, SP - Brasil. (DD https://orcid.org/00000003-0002-9009 E-mail: joel.gracioso@gmail.com
}

http://dx.doi.org/10.1590/0101-3173.2019.v42esp.09.p159 
Ora, Agostinho inicia sua análise diferenciando a falsidade da verdade. Enquanto a primeira nos leva a crer naquilo que não é, a segunda manifesta aquilo que é (AGOSTINHO, De vera religione, 36, 66) ${ }^{2}$.

Se de fato é assim, as realidades corpóreas são falsas e nos enganam? $\mathrm{Na}$ medida em que procuram assemelhar-se e imitar o Uno não, pois indicam com tal movimento sua dependência em relação ao mesmo. Todavia, na medida em que não realizam plenamente o Uno, pois refletem apenas parcialmente essa realidade suprema, sim.

As coisas são unas na medida em que participam do Uno originário, fonte de toda unidade e de tudo o que existe. Isso mostra que há um vínculo ontológico necessário entre essa realidade transcendente e os seres em geral.

Há um esforço, por parte da realidade criada, em assemelhar-se a Ele implicando um movimento de aproximação para com o Uno. Logo, todo afastamento produz uma dessemelhança.

Ora se os corpos e os seres em geral não conseguem expressar totalmente esta unidade e semelhança, e se é reprovável o movimento de afastamento, então é preciso haver um ser que consiga realizar plenamente essa aspiração e assim, expressar totalmente essa semelhança com o Uno, realizando essa tendência presente em toda realidade criada, mas que não se realiza no nível das criaturas. Este alguém é o Verbo de Deus, a própria Verdade.

Portanto, se a falsidade pressupóe essa incapacidade das criaturas em refletirem e de imitarem plenamente a suprema unidade e, por conseguinte, a presença de uma dessemelhança, entáo a Verdade é justamente a realidade pela qual se efetiva tal realização, pois ela não é inferior ao Uno, é tal como Ele, sendo a semelhança em plenitude. Por isso também pode ser chamada de Verbo, de Luz, por que mostra, manifesta o Uno tal como Ele é.

Assim, se percebe que as coisas na medida em que são ou existem possuem já certa semelhança com o Uno devido ao vínculo ontológico inerente entre a realidade criada e a realidade criadora. Ou seja, o tipo de existência da criatura pressupóe uma relação necessária com o Uno Supremo, pois elas não existem a partir de si mesmas. E, assim, no seu existir elas já refletiriam de certa forma a unidade incriada.

${ }^{2}$ Cf. AGOSTINHO, A. A verdadeira religiāo. Tradução: Paula Oliveira e Silva e Manuel Francisco Ramos. Doravante usaremos a abreviação $V R$. 
Logo, para Santo Agostinho, parece haver dentro do mundo criado ordenadamente por Deus, modos de existência ou de ser conforme o grau de semelhança e de veracidade de cada ser referido. Isso é, as coisas foram pensadas e criadas por Deus recebendo certa semelhança.

Desta maneira, na medida em que existem, já são verdadeiras e enquanto se assemelham o são. Mas, na medida em que se afastam do Uno, vão gerando uma dessemelhança e, por conseguinte, uma perda de ser e de veracidade.

Entretanto, com a Verdade não é assim, justamente porque ela não possui uma unidade, semelhança e veracidade por participação, por imitação. Ela não é por um outro, é tal como o Uno, com a mesma dimensão ontológica. Desta maneira, sendo a perfeita semelhança, não é apenas verdadeira, mas a própria Verdade.

Deste modo, se tudo o que é semelhante, é semelhante pela semelhança, e se tudo o que é verdadeiro, é verdadeiro pela Verdade, e se com o Verbo de Deus não é assim que ocorre, então o Verbo de Deus é a Verdade, pois é a própria semelhança do Uno. Ele é a Forma de tudo o que é e a Verdade, pois não tem nenhuma dessemelhança.

Enfim, as coisas verdadeiras são verdadeiras na medida em que são, ou seja, pelo simples fato de serem já são verdadeiras. E são na medida em que se assemelham a essa Realidade Transcendente. Assim, se as criaturas são, isso mostra que possuem vestígios desta semelhança pelo simples fato de existirem e manterem um vínculo ontológico com o Uno tentando imitá-lo. Mas concomitantemente também sempre haverá na criatura, pelo simples fato de ser criatura, uma dessemelhança, pois não realiza plenamente essa semelhança. Isto posto, de onde procede então a falsidade?

Para Agostinho, a falsidade não vem nem do ato de imitar limitadamente o Uno apresentando uma semelhança relativa, pois esse esforço de imitar é próprio da realidade criada, nem da falácia dos sentidos, pois esses, devido à natureza da afecção corpórea, nada mais comunica do que suas alteraçóes. Mas sim dos pecados que enganam as almas na medida em que buscam o verdadeiro desprezando, negligenciando a Verdade. Preferindo, amando, desejando, mais a obra do que o Artífice e sua Arte (o Verbo Divino). As criaturas humanas, portanto, cometeram um erro e devido a esse erro foram punidas a tal ponto que ao procurarem o criador por intermédio de sua obra, acabam julgando a obra como se essa fosse o Artífice e sua Arte (AGOSTINHO, VR, 36, 67). 
Aqui está a origem de toda impiedade. O pecado do primeiro homem foi justamente o mau uso do livre-arbítrio, um uso indevido, gerando, assim, consequências negativas e destrutivas. Isso provocaria então uma ruptura absoluta entre o humano e o divino?

Do ponto de vista agostiniano náo, pois Deus criou e continua sustentando tudo o que criou. Logo, tudo o que existe, existe em Deus, por que está em Deus. Assim, nada escapa a Deus e tudo depende Dele, não havendo possibilidade de a criatura romper totalmente com seu criador. Porém, e o pecado? O homem orgulhoso não se afastou do seu Senhor se esquecendo de sua real origem?

Mesmo o afastamento e esquecimento do homem, em relação a Deus, por intermédio do pecado, não é absoluto, pois ainda que o homem desça ao mundo inferior, Deus aí também está. Isto quer dizer que o pecado, portanto, não tem o poder de romper essa relação ontológica da criatura para com o seu criador. Não é possível um afastamento absoluto de Deus.

Desta maneira, Deus está no homem por que antes o homem está nele. Isto é, pelo fato de existir em Deus, sendo impossível não ser assim, devido à sua dependência ontológica, por isso o homem pode dizer que Deus existe nele. É porque Deus já possui o homem e o contém, por isso um dia o homem poderá possuí-lo, isto é, contemplá-lo para sempre vivenciando a fruição plena. Quais seriam então as consequências deste erro, pecado ou ato indevido?

\section{As CONSEQUÊNCIAS}

A consequência primeira deste ato é a idolatria, ou seja, preferir o simulacro e não a fonte originária absoluta de todas as coisas. $\mathrm{O}$ ser humano adora a criatura no lugar do criador. Alguns adoram a própria alma, outros a vida fecunda; depois os animais; em seguida os seres meramente corporais sem vida, começando pelos mais belos, por exemplo o sol; outros a lua, ou o firmamento todo com as estrelas; por fim olhando a totalidade dos seres entende que isso seja o único Deus grandioso (AGOSTINHO, $V R, 37,68$ ).

Após esse processo, se passa a cultuar o que o próprio homem produz, como por exemplo, seus próprios pensamentos. Até que alguém consegue vislumbrar a impossibilidade de se encontrar algo digno de ser cultuado. Nada merece adoração. Desta maneira, segundo essa perspectiva, o que de fato existe 
é uma realidade de escravidão pois os homens se envolveram com superstiçóes e se submeteram a coisas que não são dignas de tal ato.

Todavia, segundo o doutor de Hipona, isso é falso pois aqueles que se negam em prestar um culto, seja a quem for, também se submetem a determinadas realidades, principalmente à tríplice concupiscência: voluptatis, excellentiae, spectaculi, prazer, ambição e curiosidade. Agostinho duvida que entre esses homens seja possível encontrar alguém que não esteja sujeito ao prazer carnal, ao poder vão e aos espetáculos. Ora, na medida em que amam as coisas temporais pressupondo que elas vão lhes garantir a felicidade, isso implica estabelecer uma relação assimétrica e de dependência para com essas coisas. Assim, buscando a vida feliz nelas e não na Verdade, continuamente têm medo de perdê-las fazendo tudo o que for solicitado por elas para garantir a permanência das mesmas. Esse processo de amor desordenado gera uma realidade de servidão, se passa a servir as criaturas em vez do criador.

Entretanto, como tudo o que está submetido ao tempo, essas realidades também são transitórias, logo impossíveis de serem perpetuadas e, por conseguinte, de garantir a vida feliz (AGOSTINHO, $V R, 38,69$ ).

Desta forma, aqueles que para não se escravizarem se recusaram em adorar qualquer ser, eles mesmos se tornaram escravos de outras coisas inferiores a eles.

Assim, o homem ao querer ter uma independência absoluta de Deus se tornou escravo de outras realidades, colocando-se numa condição de extrema miserabilidade onde predomina os três grandes vícios ou desordens: a concupiscência da carne, dos olhos e a ambição dos séculos. A sensualidade, a curiosidade e o orgulho passam a ter uma força muito grande sobre a realidade humana, indicando assim a situação difícil dos amantes dos prazeres mais baixos, dos curiosos e dos soberbos (AGOSTINHO, $V R, 38,70$ ).

Entretanto, o homem pode se desvencilhar deste estado desde que aceite primeiramente crer naquilo que ainda não compreende. E também mude sua relação de amor com as coisas temporais, desejando-as a partir do seu grau de perfeição e semelhança com a realidade divina.

O próprio Verbo encarnado mostrou as três tentaçóes a que se deve ter uma atenção maior: transformar a pedra em pão indica a necessidade de domar-se o desejo do prazer; o prostrar-se perante o diabo mostra a busca pelo poder e a resistência a tal ato mostra a soberba pisoteada e o reconhecimento 
da soberania absoluta de Deus; o jogar-se do alto do Templo representa a curiosidade e a negação de prostrar-se explicita que não há necessidade de coisas novas e nem de artimanhas para tornar visíveis as coisas de Deus. De fato, aqueles que se alimentam interiormente da palavra de Deus não buscam o prazer de forma táo ávida nesta vida; quem se submete à Deus não corre atrás da vanglória. E aquele que vislumbra o espetáculo da verdade imutável não tem mais apetite por um tipo de saber fundamentado em realidades inferiores. Porém, como conquistar ou recuperar tal condição?

Se faz necessário, portanto, realizar um caminho de retorno ao princípio originário, dos vícios a essa beleza primordial. Mas de que modo?

\section{ORDEM, BELEZA E INTERIORIDADE}

Para Agostinho, a alma precisa realmente se recordar daquela beleza. Mas existirá algo que não possa ajudá-la nesse empreendimento, já que até os seus vícios podem auxiliar em tal tarefa? (AGOSTINHO, VR, 38, 72). Articulando uma cosmovisão cristã com referenciais neoplatônicos, ele indicará como primeira etapa nesse itinerário a observação da beleza do mundo e assim apreender a unidade. E num segundo momento, a apreensão da harmonia (LAGOUANÈRE, 2012, p. 329).

A obra da criação realizada por Deus é permeada de ordem, de beleza e possui uma dimensão teleológica. Esse modo de ser da criação, na sua totalidade, expressa a ação e a presença da Sabedoria de Deus nessa realidade criada (LAGOUANÈRE, 2012, p. 329). Assim, toda beleza manifestada no mundo nada mais é do que um reflexo do princípio absoluto. Mesmo com o pecado, as criaturas não perderam essa beleza participada.

O Salmo 138, 7 diz: "Para onde ir, longe do teu sopro? Para onde fugir, longe de tua presença?” (BIBLIA DE JERUSALÉM, 2011).

Este trecho bíblico, tão caro a Agostinho, invoca justamente a onipresença de Deus. Por mais que a criatura tente se afastar do Criador, é impossível existir de maneira absolutamente distante dele. Deus não só chamou tudo à existência, mas permeia toda a sua obra. Ele é o fundamento último da realidade e sustenta tudo o que existe. Assim, ele é aquele que melhor conhece sua obra, de forma especial o coração da sua criatura humana. Entretanto, Deus não é apenas o princípio e o fundamento de tudo, ele também é o fim de todas as coisas, pois fomos feitos por Ele e para Ele. Devido a isso, o homem 
é um ser inquieto, um peregrino que está em busca desse absoluto, do seu princípio originário, a própria verdade e beleza absoluta. Todavia, o que é a beleza? Em que medida sua procura nos ajuda no retorno ao absoluto?

Em (VR, 32, 59) Agostinho diz:

Assim, se eu perguntar a um arquiteto por que razão, tendo construído um arco, constrói outro igual no lado oposto, responderá, creio eu, que é para que os elementos iguais do edifício correspondam com iguais. Se continuar a perguntar por que razáo optou por isso mesmo, dirá que é por ser conveniente, é por ser belo, e é por deleitar os que observam: náo ousará dizer mais. ${ }^{3}$

Vemos assim que o que parece atrair o olhar do arquiteto é a simetria ou igualdade entre as partes, pois ela é bela. Entretanto, qual é o fundamento do belo sensível, será a simetria?

Parece que não, pois como lidar com aquelas realidades que possuem partes dessemelhantes e contrastantes?

Isso impõe a questão de saber: por que a simetria é bela? Uma coisa é dizer que a igualdade das partes de um corpo é bela. Mas porque essa simetria é bela?

O fato é que as simetrias estão colocadas de um jeito que pressupóe ou evoca a presença da unidade e da harmonia. Desta forma, algo simétrico é belo porque é harmonioso, e isso implica também a unidade. Portanto, na perspectiva de Agostinho, pode se afirmar que o que torna algo simétrico ou não simétrico belo, é a unidade ou a harmonia que conduz a ela.

Ora, a partir do seu referencial ontológico e cosmológico, o bispo de Hipona consegue estabelecer que há uma beleza presente seja em cada criatura particular, pois tudo o que é, é uno. Como também do ponto de vista da totalidade do cosmos, pois há uma unidade na própria estrutura e organização do cosmos.

Enfim, para Agostinho se

formos enganados pela beleza das coisas visíveis - pois por um lado são sustentadas pela unidade, e por outro náo a realizam de modo perfeito compreendamos, se pudermos, que náo somos enganados por aquilo que é, mas por aquilo que não é. Na verdade, todo o corpo é um verdadeiro corpo, mas uma falsa unidade. De facto, não é o uno supremo ou, ao

\footnotetext{
${ }^{3}$ Cf. Agostinho, A. DV 32, 59.
} 
menos, não o imita ao ponto de o realizar plenamente. E, contudo, ele próprio não seria corpo a não ser que fosse de algum modo uno. Por outro lado, náo poderia ser de algum modo uno, a não ser que o recebesse daquele é a suprema unidade. (AGOSTINHO, $V R, 34,63$ ).

Desta maneira, quando alguém ama um corpo, ou busca o prazer, por exemplo, ama a harmonia, a conveniência manifestada por ele pois o desacordo produz dor, enquanto a concórdia gera prazer. Assim, ao se interrogar sobre o que atrai o amante naquilo que é amado se verá que nada mais é do que a harmonia que está ali. Todavia, essa harmonia é uma realidade relativa pois remete a uma outra absoluta e suprema.

Santo Agostinho reconhece que a obra da criação no seu todo, o céu e a terra, diz a todos os homens, constantemente, que devemos reconhecer qual seja a Suprema Harmonia. O mundo natural, sensível, pelo seu modo de ser já indica sua realidade de dependência total em relação à Realidade Divina.

Entretanto, nem todos conseguem perceber os vestígios dessa Suprema Beleza nas criaturas e, por conseguinte, não reconhecem qual seja a Suprema Harmonia. Por quê?

\subsection{A interioridade}

Em vários momentos, no seu itinerário e nas suas obras, Agostinho salienta a importância do conhecimento de si, da reflexividade, da interioridade. A verdadeira religião é um desses momentos (LAGOUANÈRE, 2012, p. 325331). O retorno e o reconhecimento da Suma Harmonia não se dão a partir do exterior, com os olhos sensíveis e seus critérios, mas sim a partir do homem interior e no mais íntimo dele.

Em Agostinho (VR, 38, 72) lemos:

Não te dirijas para fora, regressa a ti mesmo; no homem interior habita a verdade; e, se deparares com a tua natureza mutável, ultrapassa-te a ti próprio. Mas recorda que, quando te ultrapassas, transcendes a alma racional: tendes, portanto, para onde o próprio lume da razáo se acende. De facto, onde chega todo aquele que faz um uso da razáo, a náo ser à verdade? A verdade certamente não se alcança a si própria raciocinando, mas ela própria é aquilo que desejam os que raciocinam. Aí veras uma conveniência à qual nenhuma outra se sobrepóe e tu próprio faz para estar em acordo com ela. Confessa que tu não és o que ela própria é: pois de 
facto ela não se procura a si própria; tu, porém, procurando-a, alcançaste-a - não através de lugares espaciais, mas com o afeto da mente - a tal ponto que o próprio homem interior entra em concordância com aquele que o habita, náo por meio do prazer ínfimo da carne, mas pelo supremo e espiritual prazer.

Vemos, a partir desse trecho, que não basta olhar e apreender o mundo por intermédio dos sentidos. É preciso transcender o registro da exterioridade e adentrar o âmbito do homem interior, pois somente essa mudança de caminho e registro permitirá o homem continuar seu itinerário de retorno. Portanto, para se retornar ao divino, beleza absoluta e Verdade Suprema, fonte de toda beleza presente nos seres criados, se pressupóe não mais abarcar as coisas apenas pelos sentidos externos, mas agora principalmente pela via da interioridade pois a verdade habita o homem interior.

A interioridade para Agostinho, por um lado, indica a realidade do homem interior e a inspeção do próprio espírito. Mas também aponta para a ideia de um movimento interiorizante e ascensional. Por intermédio de sua mente $^{4}$, o homem vai adentrando os vários degraus da alma, tendo como critério a mutabilidade, e raciocinando constata não uma ideia, mas sim a presença de algo que transcende o próprio homem interior (VAZ, 2001, p. 87). Ou seja, na medida em que a realidade criada é intrinsicamente mutável e a verdade desejada é imutável, é necessário ir além de si mesmo, em direção àquela realidade tão almejada pela própria razão, porque ficar preso a si mesmo é ficar estagnado na mutabilidade e não atingir o fim almejado.

Assim, no registro de interioridade pela análise efetuada pela mente é possível vislumbrar aquilo que antes não se conseguiria, isto é, uma harmonia ou conveniência que nenhuma outra consegue ultrapassar. $\mathrm{O}$ olhar interior possibilita ver uma realidade imutável e compreendê-la de forma não espacializante. Consegue encontrá-la não como se encontra algo que está em

\footnotetext{
${ }^{4}$ A mente (mens) para Santo Agostinho não se confunde com a totalidade da alma (animus), mas sim com a sua dimensão mais nobre contendo nela tanto a razão (ratio) como a inteligência (intellegentia), conforme nos diz na Cidade de Deus XI, 2: "Mas como a própria parte mental, sede natural da razão e da inteligência."

Vemos assim, que na mente está presente tanto a razão como a inteligência. A razão é o movimento pelo qual o pensamento distingue ou associa diferentes conhecimentos adquiridos ( $A$ ordem $\mathrm{II}, 11,30)$. Está subordinada à inteligência e/ou intelecto, termos que possuem certa equivalência, pois indicam uma faculdade superior à razão (GILSON, 1987, p. 57). Assim, sendo imagem de Deus e contemplando a verdade por intermédio de uma visão interior, a mente pode ser vista como a dimensão superior da alma. (AGOSTINHO, A Trindade XV, 7, 11).
} 
um determinado lugar do espaço. Mas sim como uma realidade incorpórea, inteligível. Não é algo físico, sensível, que percebemos pelos nossos sentidos exteriores, mas algo totalmente distinto, que, entretanto, abrange tudo com sua grandeza.

Supera-se, assim, a partir da interioridade, todo referencial materialista ou corporalista na compreensão desta harmonia suprema. Percebe-se, ademais, a diferença radical do criado em relaçáo a ela pois, o humano para entrar em concordância com ela precisa procurá-la adequadamente, isto é, pela mente e náo como se fosse algo exterior e espacializante. E na medida em que vai descobrindo-a e alcançando-a, o homem interior vai se adequando à mesma. Estabelece-se, desta maneira, uma concordância entre o homem interior e aquilo que o habita.

A interioridade, portanto, nos permite, segundo Santo Agostinho, reconhecer a ordem e a beleza na obra de Deus e, por conseguinte, reconhecer a Suma Harmonia. É preciso ir não para fora, mas sim regressar a si mesmo. Não no sentido de uma egolatria e sim numa atitude de inspeção do próprio espírito, e descobrir aí Aquele que é mais íntimo do que minha própria intimidade. É neste instante que se revela a dimensão teológica da interioridade agostiniana.

\section{CONSIDERAÇÓES FINAIS}

Enfim, a partir dessa mudança de postura, voltando-se não mais para a o exterior e sim para o âmbito da interioridade, o homem interior vai a cada dia se renovando e o homem exterior vai se corrompendo (AGOSTINHO, $D V, 40,74 . s t)$. Mas isso não implicaria numa condenação do homem exterior, identificando apenas o interior ao belo, enquanto o exterior ao corrompido e feio? Seria isso um resquício de maniqueísmo no pensamento agostiniano?

Não, porque o homem exterior, corpóreo, possui uma harmonia que lhe é própria. Tem condiçôes, por exemplo, de assimilar, pelos alimentos, aquilo que o beneficiará. A partir disso aquilo que se incorpora a ele náo mantém mais a própria forma, e sim transita, harmoniosamente, a uma outra pela seleçáo realizada naturalmente pelo próprio organismo. $\mathrm{O}$ que for apto será assimilado pela estrutura do homem exterior, essa beleza visível. O que não for será expulso de várias maneiras distintas. 
Aqui está de fato, segundo Agostinho, o domínio do prazer e da beleza inferior, porque está submetida à corrupção, ou seja, a todo esse processo de mudança e perda de forma. Entretanto não seria o que é se não fosse assim. Estaríamos diante da beleza absoluta e náo de uma realidade criada.

A divina providência (AGOSTINHO, $D V$, 40, 75) mostra que a beleza e o modo de ser do corpo não é algo mau, pois se por um lado se manifesta nele dores, doenças ou deficiências, há também vestígios das realidades primeiras presente no cosmos em geral. Essa ambiguidade não condena a corporeidade. Náo a transforma em algo mau. Indica, apenas, que é necessário ir além dela buscando o Imutável. Para nos convencer desta necessidade, a providência se utiliza de tudo, até das realidades inferiores, sejam anjos maus ou homens pervertidos.

Desta maneira, tudo o que existe, seja pelo que faz ou pela finalidade inerente à sua natureza, está ordenado para a beleza do conjunto. Todavia, essa constatação só é possível na medida em que não se olha apenas uma parte do todo e sim a totalidade da obra da criação. Algo isoladamente pode nos desagradar, mas no conjunto se percebe o seu sentido e função. É um equívoco, portanto, julgar a obra da criação por uma parte. É preciso conhecer a totalidade da mesma para emitir um juízo correto. Ao julgar-se, por exemplo, um prédio não podemos ficar presos apenas a um ângulo, pois correríamos o risco de não julgarmos devidamente (AGOSTINHO, $D V$, 40, 76).

Logo, aquilo que é imperfeito nas partes, é perfeito no conjunto e é percebido como algo belo. Não entender isso implica cometer um erro feio e pernicioso que levaria à negação da beleza da obra divina. Por conseguinte, o único mal de fato é o pecado, que consistiu no afastamento voluntário da suma essência, fundamento último de todo ser, beleza e harmonia.

Assim, na medida em que o homem entende, aceita e realiza o processo de retorno ao absoluto, tem condiçóes de superar a impiedade e a idolatria, recordando e reconciliando-se com o absoluto divino, princípio originário de criação. Contudo, isso só é possível a partir do momento em que o homem consegue perceber a ordem e a beleza do mundo criado, e reconhecer, também, a suprema harmonia. Feito realizável, segundo o mestre do Ocidente, apenas se adentrarmos a via da interioridade. 
GRACIOSO, J. Idolatry, order, and beauty: the path of the return to the Absolute in Augustine's De vera religione. Trans/Form/Ação, Marília, v. 42, p. 159-170, 2019. Edição Especial.

ABstract: This article discusses the relationship between idolatry, order, beauty, and interiority in Augustine's De vera religione.

KEYworDs: Idolatry. Order. Beauty. Interiority.

\section{REFERÊNCIAS}

AGOSTINHO, A. A cidade de Deus. Tradução: J. Dias Pereira. Lisboa: Fundação Calouste Gulbenkian, 1996.

AGOSTINHO, A. A Trindade. Tradução: Arnaldo do Espírito Santo, Domingos Lucas Dias, João Beato e Maria Cristina de Castro-Maia de Souza Pimentel. Coimbra: Paulinas, 2007. (Edição bilíngue).

AGOSTINHO, A. A verdadeira religião. Tradução: Paula Oliveira e Silva e Manuel Francisco Ramos. Porto: Ediçóes Afrontamento, 2012. (Edição bilíngue).

AGOSTINHO, A. De la verdadeira religión. In: Obras completas San Agustín. Traducción: Victorino Capánaga. Madrid: BAC, 2011. V. 4. (Edición bilíngue).

AGOSTINHO, A. Diálogo sobre a ordem. Tradução: Paula Oliveira e Silva. Lisboa: Imprensa Nacional; Casa da Moeda, 2000.

BÍBLIA DE JERUSALÉM. Nova edição rev. e ampl. São Paulo: Paulus, 2011.

GILSON, É. Introdução ao estudo de Santo Agostinho. Tradução: Cristiane Negreiros Abbud Ayoub. São Paulo: Paulus; Discurso Editorial, 2006.

LAGOUANÈRE, J. Intériorité et réflexivité dans la penseé de Saint Augustin: formes et genèse d'une conceptualisation. Paris: Institut d'Études Augustinienne, 2012.

VAZ, H. C. L. A metafísica da interioridade. In: Ontologia e história. São Paulo: Loyola, 2001. p. 77-87.

Recebido: 30/12/2019

Aceito: 30/12/2019 